\title{
The anti-inflammatory effects of a high-frequency oligodeoxynucleotide from the genomic DNA of Lactobacillus casei
}

Yukihiro Hiramatsu ${ }^{\mathrm{a}}$, Tomomitsu Satho ${ }^{\mathrm{a} *}$, Mika Hyakutake ${ }^{\mathrm{a}}$, Keiichi Irie ${ }^{\mathrm{a}}$, Kenichi Mishima ${ }^{\mathrm{a}}$, Fumio Miake $^{a}$, Nobuhiro Kashige ${ }^{a}$

${ }^{\text {a }}$ Faculty of Pharmaceutical Sciences, Fukuoka University, 8-19-1, Nanakuma, Jonan-ku, Fukuoka 8140180, Japan

* Corresponding author: Tomomitsu Satho

8-19-1, Nanakuma, Jonan-ku, Fukuoka 814-0180, Japan.

Tel: +81-92-871-6631 (ext. 6613). Fax: +81-92-863-0389. E-mail: satho@fukuoka-u.ac.jp

Conflicts of interest: The authors have no conflicts of interest to disclose.

Funding: This work was supported by the following grants: JSPS KAKENHI (No. 24659060 and 26460181); Adaptable and Seamless Technology transfer Program through target-driven R\&D (A-STEP) of Japan Science and Technology Agency (No. AS231Z02003G); the Central Research Institute of Fukuoka University (No. 126012 and 127007). 


\section{Abstract}

Genomic DNA has been identified as an anti-inflammatory component of Lactobacillus species, the effects of which are mediated through toll-like receptor (TLR) 9. In this study, we identified 14 novel anti-inflammatory oligodeoxynucleotide (ODN) from the genomic DNA of Lactobacillus casei by measuring their effects on the secretion of interleukin (IL)-8 (CXCL8) in the human epithelial colorectal adenocarcinoma cell line Caco-2 cells. The ODN TTTTGCCG strongly decreased IL-8 secretion. In the genomic DNA of Lactobacillus species, the frequency of TTTTGCCG was highest in the genomic DNA of $L$. casei and similar among strains of L. casei. Decreases in inducible nitric oxide synthase (iNOS) and cyclooxygenase (COX)-2 expressions in macrophage-like differentiated THP-1 cells confirmed the anti-inflammatory effect of TTTTGCCG. Furthermore, oral administration of TTTTGCCG ameliorated dextran sodium sulfate (DSS)-induced murine colitis and DSS-induced increased expression of inflammatory factor mRNAs, such as macrophage inflammatory protein (MIP)-2 (CXCL2), iNOS, and COX-2. The anti-inflammatory effect of TTTTGCCG was mainly regulated by an increase in heat shock protein (Hsp) 70 expression in the epithelium. TLR9 and Hsp90 may primarily mediate the antiinflammatory effect of TTTTGCCG on Hsp70 signaling.

Keywords: anti-inflammatory effect; heat shock protein; Lactobacillus casei; oligodeoxynucleotide; tolllike receptor 9 


\section{Introduction}

Lactobacillus species, which are normal components of the human gut microflora, can be beneficial to the health of the host. For example, therapy using live Lactobacillus species has been reported to ameliorate human intestinal inflammation, which occurs in inflammatory bowel disease (IBD), including Crohn's disease and ulcerative colitis, caused by chronic inflammation of the intestine [1]. The genomic DNA and cell wall components of Lactobacillus species have been identified as components of this antiinflammatory effect [2, 3]. In a previous study, we showed that genomic DNA of five Lactobacillus species_Lactobacillus acidophilus, Lactobacillus casei, Lactobacillus gasseri, Lactobacillus plantarum, and Lactobacillus reuteri-decreased $\mathrm{H}_{2} \mathrm{O}_{2}$-induced interleukin (IL)-8 (CXCL8) secretion, an inflammatory indicator, in the human epithelial colorectal adenocarcinoma cell line Caco-2 [4]. Furthermore, we observed that the anti-inflammatory effect of genomic DNA from L. acidophilus is weaker than those of genomic DNAs from other species. In a recent study, live L. acidophilus was shown to decrease the secretion of IL-8 induced by lipopolysaccharide (LPS), interferon (IFN)- $\gamma$, and Salmonella enterica in human epithelial HT-29 cells and Caco-2 cells. However, the effects were weaker than those of other Lactobacillus, Lactococcus, and Bifidobacterium species [5, 6]. Therefore, the antiinflammatory effects of live Lactobacillus species and genomic DNA of Lactobacillus species differ between species. The correspondence between the anti-inflammatory effects produced by live Lactobacillus species and genomic DNA of Lactobacillus species suggests that genomic DNA is the principal anti-inflammatory component.

Oligodeoxynucleotide (ODN) is short single-stranded DNA molecules generally consisting of less than 30 nucleotides. Some ODN can have immunostimulatory effects, such as inducing B cell 
proliferation [7], increasing levels of chemokines, such as macrophage inflammatory protein (MIP)-2 (CXCL2) (murine counterpart of human IL-8) [8], and exacerbating the effects of dextran sodium sulfate (DSS)-induced colitis [9]. Lactobacillus rhamnosus can induce dendritic cell maturation, B cell proliferation, and secretion of immunoglobulin A from the intestinal mucosa thereby protecting against diarrheal disease caused by pathogenic bacterial infection [10, 11]. Iliev et al. showed that genomic DNA contribute to the immunostimulatory effect induced by L. rhamnosus [12], and they identified an immunostimulatory ODN (TTTCGTTT) from a genomic DNA library of L. rhamnosus by screening for effects on B cell proliferative in murine splenocytes. However, other ODN exert anti-inflammatory effects, such as inhibiting B cell proliferation [13] and IL-8 secretion [14] and ameliorating DSSinduced colitis [2]. Anti-inflammatory ODN have been identified from the genomic DNA of bacteria other than Lactobacillus species or designed to bind to specific bacterial DNA receptors, such as toll-like receptor (TLR) 9 [15], and transcription factors, such as nuclear factor (NF)-кB [16]. Stacey et al. identified two anti-inflammatory ODN (TTAGGG and TCAAGCTTGA) by comparing the genomic DNA of Escherichia coli and mouse [13], and Bouladoux et al. reported that the frequencies of the two anti-inflammatory ODN in the genomic DNA of Lactobacillus paracasei were higher than those in the genomic DNA of E. coli, whereas the frequencies of two immunostimulatory ODN (AACGTT and ATCGAT) did not differ markedly between L. paracasei and E. coli [17]. They suggested that the frequency of anti-inflammatory ODN in the genomic DNA of Lactobacillus species may determine the anti-inflammatory effects of genomic DNA. However, the frequencies of TTAGGG and TCAAGCTTGA in the genomic DNA of Lactobacillus species did not correspond with differences in the anti-inflammatory effects of the genomic DNA. Therefore, the genomic DNA of Lactobacillus species may contain other unique anti-inflammatory ODN that determine the anti-inflammatory effects of each species. 
Inflammatory stimulation by excessive reactive oxygen species, such as $\mathrm{H}_{2} \mathrm{O}_{2}$, and bacterial components, such as LPS, trigger the overproduction of IL-8 by intestinal epithelial cells (IECs), which cover a vast area of the intestinal mucosa as a single layer $[18,19]$. Production of IL-8 is one of the major cascades involved in intestinal inflammation. An excess of IL-8 triggers the recruitment of various types of immune cells, such as monocytes, leukocytes, and neutrophils, from the blood to the lamina propria of the intestine [20]. The monocytes differentiate into macrophages that express enzymes associated with inflammation, such as inducible nitric oxide synthase (iNOS) and cyclooxygenase (COX)-2. These inflammatory enzymes induce prostaglandin and nitric oxide (NO) production, followed by the expression of other inflammatory factors, such as inflammatory cytokines and chemokines, from neighboring IECs and immune cells. In the interaction between IECs and immune cells during intestinal inflammation, TLR9 is the primary mediator of the anti-inflammatory effects of Lactobacillus species [21, 22]. Rachmilewitz et al. reported that the severity of DSS-induced murine colitis in wild-type mice was significantly decreased by oral administration of live Lactobacillus species, but in TLR9-deficient mice, live Lactobacillus species had no effect [2]. In addition, we have shown that genomic DNA of Lactobacillus species does not decrease $\mathrm{H}_{2} \mathrm{O}_{2}$-induced IL-8 secretion in Caco-2 cells when TLR9 expression was suppressed by RNAi [4]. Therefore, TLR9 may be one of the primary mediators of the effects of anti-inflammatory ODN from Lactobacillus species. On the other hand, Bandholtz et al. reported that an ODN (ACCGATAACGTTGCCGGTGACG), which ameliorates DSSinduced murine colitis [2], binds to heat shock protein (Hsp) 90 [23]. The binding to Hsp90 followed by inhibition of its ATPase activity, led to increased expression of Hsp70, an intracellular anti-inflammatory factor [24]. Malago et al. reported that L. casei increased the expression of Hsp70 in Caco-2 cells, whereas Lactobacillus salivarius had no such effect. Interestingly, they also showed that L. casei decreased S. enterica-induced IL-8 secretion, but they observed no such effect with L. salivarius [6]. Furthermore, DSS-induced murine colitis was less severe in Hsp70-overexpressing transgenic mice than 
in wild-type controls [25]. These observations suggest that an increase in Hsp70 expression is one of the signals responsible for the anti-inflammatory effect of Lactobacillus species. Therefore, an increase in Hsp70 expression induced by ODN stimulation of TLR9 and/or binding to Hsp90 may mediate the effects of anti-inflammatory ODN.

The present study was performed to identify and characterize a unique anti-inflammatory ODN in the genomic DNA of $L$. casei. We screened for anti-inflammatory ODN isolated from genomic DNA of L. casei by measuring their effects on IL-8 secretion in epithelial cells. We subsequently determined the frequency of the identified anti-inflammatory ODN in the genomic DNA of five Lactobacillus species. Furthermore, to confirm the anti-inflammatory effects of the ODN on intestinal inflammation, we measured iNOS and COX-2 levels in immune cells. In addition, we examined whether oral administration of the anti-inflammatory ODN ameliorates DSS-induced murine colitis and decreases the DSS-induced increase in inflammatory factors (i.e., MIP-2, iNOS, and COX-2). Finally, we confirmed the involvement of TLR9 and Hsp70 in the anti-inflammatory effect of the ODN in the epithelium.

\section{Materials and methods}

\section{2-1. Bacterial strains}

The strains used in this study were L. casei ATCC 27092 and E. coli DH5 $\alpha$. L. casei was grown at $37^{\circ} \mathrm{C}$ 
in MRS-broth without shaking, and E. coli was grown at $37^{\circ} \mathrm{C}$ in LB-broth with shaking.

\section{2-2. Cell culture}

Caco-2 cells were used as described previously [4]. The human monocytic leukemia cell line THP-1 was obtained from the American Type Culture Collection (ATCC, Manassas, VA) and were cultured in RPMI-1640 medium (Invitrogen, Carlsbad, CA) supplemented with 10\% fetal bovine serum (Biowest, Nuaile, France), 1\% penicillin (Sigma-Aldrich, St. Louis, MO), 1\% streptomycin (Sigma-Aldrich), and 1\% sodium pyruvate (Nacalai Tesque, Kyoto, Japan). Cells were cultured in $75-\mathrm{cm}^{2}$ tissue culture flasks (BD, Franklin Lakes, $\mathrm{NJ}$ ) at $37^{\circ} \mathrm{C}$ in $5 \% \mathrm{CO}_{2}$. THP-1 cells were differentiated to macrophage-like cells by treatment with $100 \mathrm{ng} / \mathrm{ml}$ phorbol 12-myristate 13-acetate (PMA) (Sigma-Aldrich) for $48 \mathrm{~h}$ before use in experiments.

\section{2-3. Animals}

Six-week-old male C57BL/6N mice (Kyudo Experimental Animal Laboratory, Saga, Japan) were used in this study. All procedures related to the animals and their care were approved by the Experimental Animal Care and Use Committee of Fukuoka University (approval number: 1204553). 


\section{2-4. Cloning of plasmids containing DNA fragments from the genomic DNA of L. casei}

The genomic DNA of $L$. casei was extracted from an overnight culture of $L$. casei with a Gentra Puregene Yeast/Bact kit (Qiagen, Hilden, Germany). Genomic DNA was digested with Sau3AI (Roche, Laval, QC, Canada), and the DNA fragments were separated by agarose gel electrophoresis. Fragments of 200 - 1000 bp were extracted from the gel using a MonoFas DNA Purification kit (GL Sciences, Tokyo, Japan) and ligated with T4 DNA ligase (Takara Shuzo, Kyoto, Japan) into the BamHI site of the pUC19 vector (Takara Shuzo). The recombinant plasmids were transformed into E. coli, and the transformants were screened by direct PCR using the following primers: pUC19-Fw-315 (5'AAAGGGGGATGTGCTGCAAGGCG-3') and pUC19-Rv-515 (5'-

CGGGATCCCCCCGCTAGGGACC-3'). One hundred transformants were chosen at random, and the plasmids were isolated with Wizard Plus SV Minipreps DNA Purification System (Promega, Madison, WI). Contaminating LPS was removed from the plasmids with a MiraCLEAN Endotoxin Removal kit (TaKaRa Bio, Shiga, Japan).

\section{2-5. Measurement of IL-8 secretion}

The secretion of IL-8 from Caco-2 cells was measured by ELISA as described previously [4]. Aliquots of $2 \times 10^{5}$ Caco-2 cells were plated in each well of 24-well plates (Nunc, Rochester, NY). Cells were treated with $10 \mu \mathrm{g} / \mathrm{ml}$ plasmid or $30 \mu \mathrm{M}$ ODN chemically synthesized by GeneNet (Fukuoka, Japan) in the presence of $1 \mathrm{mM} \mathrm{H}_{2} \mathrm{O}_{2}$ for $48 \mathrm{~h}$. After incubation, cell supernatants were centrifuged at 15,000 $\times g$ 
for $5 \mathrm{~min}$ at $4^{\circ} \mathrm{C}$. The concentration of IL-8 in the cell supernatants was determined with a human IL-8 ELISA kit (R\&D Systems, Abingdon, UK).

2-6. Determination of high-frequency sequences in nucleotide fragments from the genomic DNA of $\mathrm{L}$. casei

Sequencing PCR was performed with the primers pUC19-Fw-315 and pUC19-Rv-515 using a BigDye terminator v3.1 Cycle Sequencing kit (Applied Biosystems, Foster City, CA). PCR products purified by ethanol precipitation were sequenced using an ABI PRISM 310 Genetic Analyzer (Applied Biosystems). Common sequences in plasmids containing nucleotide fragments from the genomic DNA of $L$. casei were identified using GENETYX version 11.

\section{2-7. Surveillance of content rate of ODN in genomic DNA from five Lactobacillus species}

Genome data were downloaded from the NCBI genome database for three strains of $L$. acidophilus, seven strains of $L$. casei, one strain of L. gasseri, six strains of L. plantarum, and five strains of $L$. reuteri (Supplementary Table 1). The occurrences of the sequences of 14 ODN (3F - 9R) within the genomic DNA of Lactobacillus species were analyzed using GENETYX version 11. 


\section{2-8. Measurement of iNOS and COX-2 protein expression}

Aliquots of $3 \times 10^{6}$ THP- 1 cells were plated in each well of 6-well plates (Nunc). After the cells differentiated to macrophage-like cells, they were treated with $30 \mu \mathrm{M}$ ODN in the presence of $3 \mu \mathrm{g} / \mathrm{ml}$ LPS (Sigma-Aldrich). After incubation for $24 \mathrm{~h}$, the cellular protein extract was prepared with Lysis Buffer \#12 (R\&D Systems) according to the manufacturer's protocol, and the protein concentration was determined with Coomassie Protein Assay Reagent (Pierce, Perbio Science, Bonn, Germany). iNOS expression in the protein extract was determined by western blotting. Equal amounts of protein were separated by SDS-PAGE and transferred onto a polyvinyl difluoride membrane (GE Healthcare, Buckinghamshire, UK). An antibody to iNOS was used as the primary antibody (Cell Signaling Technology, Boston, MA). Alkaline phosphatase (AP)-labeled anti-rabbit IgG (Cell Signaling Technology) was used as the secondary antibody and detected with chemiluminescent substrate for AP (CDP-Star reagent; New England Biolabs, Beverly, MA). Equal loading was confirmed using an antibody to $\beta$-actin (Cell Signaling Technology). The band density was measured using ImageJ software [26] and presented as a ratio relative to that of $\beta$-actin. COX-2 expression in the protein extract was determined with a human COX-2 ELISA (R\&D Systems).

\section{2-9. DSS-induced murine colitis}

Colitis was induced in mice by the addition of 3\% DSS (5,000 Da; Wako Pure Chemicals, Osaka, Japan) to the drinking water for 7 days. The animals were divided into six groups: saline, DSS + saline, DSS + 
1F, DSS + 7F, DSS + 7R, and DSS + 8F. The mice were orally administered saline or 1F, 7F, 7R, or $8 \mathrm{~F}$ ( $2 \mathrm{nmol} / \mathrm{g}$ mouse) every 3 days starting 6 days before DSS treatment and for 7 days of DSS treatment.

\section{2-10. Evaluation of disease activity index (DAI) and colon length}

Body weight, stool consistency, and stool blood were recorded daily. DAI was determined by combining the scores of these three factors. The scores were determined as follows: percentage of body weight compared to day 0 (1: > 100\%, 2: 90 - 100\%, 3: $80-90 \%, 4:<80 \%)$, stool consistency (1: normal, 2:

slightly loose, 3: loose, 4: watery), and stool blood (1: normal, 2: adherence of blood to stool, 3:

adherence of blood to anus, 4: adherence of blood to whole stool and anus). Mice were sacrificed at the end of the experiment, and the colon was collected. The length of the colon was measured between the ileocecal junction and the rectum. For protein extraction, the colon was stored at $-80^{\circ} \mathrm{C}$. For total RNA extraction, the colon was submerged in RNAlater (20 mM EDTA, 25 mM sodium citrate tribasic dihydrate, $70 \%$ ammonium sulfate) at $4^{\circ} \mathrm{C}$ overnight, removed from the RNAlater, and then stored at $80^{\circ} \mathrm{C}$.

\section{2-11. Histopathology of the colon}

Mice ( $n=3$ in each group) were sacrificed and perfused with saline and 4\% paraformaldehyde. The colon was collected, depleted of fat and water with an auto-degreasing unit (RH-12; Sakura Seiko Co., 
Tokyo, Japan), and then embedded in paraffin. Subsequently, sections of the distal colon $5 \mu \mathrm{m}$ thick were mounted on slides and dried at $37^{\circ} \mathrm{C}$ overnight. The sections were stained with hematoxylin and eosin (HE) and analyzed by microscopy.

\section{2-12. Myeloperoxidase (MPO) activity assay}

The colon was homogenized in $50 \mathrm{mM}$ potassium phosphate buffer ( $\mathrm{pH} 6.0$ ) supplemented with $0.5 \%$ hexadecyltrimethylammonium bromide (Sigma-Aldrich). The lysate was frozen at $-80^{\circ} \mathrm{C}$ and thawed at $4^{\circ} \mathrm{C}$ three times. After centrifugation at $2,000 \times g$ for 5 min at $4^{\circ} \mathrm{C}$, the supernatant was collected and used as the protein extract for the MPO activity assay. The protein concentration was determined with a BCA Protein Assay kit (TaKaRa Bio). The enzyme reaction was performed in a 96-well plate (Nunc) by adding 50 mM phosphate buffer (pH 6.0), $0.167 \mathrm{mg} / \mathrm{ml}$ o-dianisidine dihydrochloride (Sigma-Aldrich), $0.05 \% \mathrm{H}_{2} \mathrm{O}_{2}$, and $100 \mu \mathrm{g}$ of protein. After incubation for $30 \mathrm{~min}$ at room temperature, the absorbance at 450 nm was measured. MPO activity was determined by comparison to a standard MPO (SigmaAldrich) curve.

\section{2-13. Measurement of MIP-2, iNOS, and COX-2 mRNA expression}

The colon was homogenized in ISOGEN (Nippon Gene, Tokyo, Japan), and total RNA was extracted according to the manufacturer's protocol. Total RNA extract was treated with an RNase-Free DNase set 
(Qiagen) and then purified with an RNeasy Plus Mini kit (Qiagen). cDNA synthesis was performed with purified total RNA using ReverTra Ace qPCR RT Master Mix (Toyobo, Osaka, Japan). Real-time quantitative PCR was performed with THUNDERBIRD SYBR qPCR Mix (Toyobo) using the StepOne Real-Time PCR System (Applied Biosystems). The primer sequences and concentrations are presented in Supplementary Table 2. The relative gene expression was calculated using the $\Delta \Delta \mathrm{Ct}$ method. The expression of target genes was normalized relative to $\beta$-actin expression as an internal control in each sample. Data are presented as the fold change compared to the saline group.

\section{2-14. Transfection of Caco-2 cells with TLR9- or Hsp70-siRNA}

The transfection of siRNA was performed as described previously [4]. Aliquots of $2 \times 10^{5}$ Caco-2 cells were plated in each well of 24-well plates. Subsequently, $0.25 \mu \mathrm{l}$ of $100 \mu \mathrm{M}$ TLR9-siRNA, scramble TLR9-siRNA, Hsp70-siRNA, or scramble Hsp70-siRNA (Supplementary Table 3) (Bonac Corp., Fukuoka, Japan) was added to $250 \mu \mathrm{l}$ of medium and incubated for $5 \mathrm{~min}$ at room temperature. The siRNA solution was then added to $250 \mu \mathrm{l}$ of medium containing $5 \mu \mathrm{l}$ of siLentFect Lipid Reagent (BioRad Laboratories, Hercules, CA) and incubated for $30 \mathrm{~min}$ at room temperature to produce the transfection mix. Cells were transfected with the transfection mix for $24 \mathrm{~h}$, after which the cells were treated with $30 \mu \mathrm{M} 1 \mathrm{~F}$ or $7 \mathrm{~F}$ in the presence of $1 \mathrm{mM} \mathrm{H}_{2} \mathrm{O}_{2}$. After incubation for $48 \mathrm{~h}$, IL-8 secretion was measured by ELISA. The suppression of TLR9 and Hsp70 expression by RNAi was confirmed by western blotting using antibodies to TLR9 and Hsp70 (Cell Signaling Technology) as described above (Supplementary Fig. 1). 


\section{2-15. Measurement of Hsp70 expression}

Aliquots of $7 \times 10^{5}$ Caco- 2 cells were plated in each well of 6-well plates. Caco- 2 cells were treated with $30 \mu \mathrm{M} 1 \mathrm{~F}$ or $7 \mathrm{~F}$ in the presence of $1 \mathrm{mM} \mathrm{H}_{2} \mathrm{O}_{2}$. Protein extracts from Caco-2 cells and the colon were prepared with PRO-PREP Protein Extraction Solution (iNtRON Biotechnology, Kyungki-Do, South Korea) according to the manufacturer's protocol. The protein concentration was then determined with Coomassie Protein Assay Reagent. Hsp70 levels in the protein extracts were assessed by western blotting using an antibody to Hsp70 as described above.

\section{2-16. Binding of ODN to rHsp90}

1F or $7 \mathrm{~F}(100 \mu \mathrm{M})$ was added to an equal volume of PHOTOPROBE Biotin (Vector Laboratories, Burlingame, CA) and then incubated for $30 \mathrm{~min}$ at $95^{\circ} \mathrm{C}$. A $250-\mu \mathrm{l}$ aliquot of the biotin-labeled ODN was added to an equal volume of Streptavidin Agarose Ultra Performance (Solulink, San Diego, CA) and then incubated for $20 \mathrm{~min}$ at room temperature. The agarose resin-conjugated ODN was washed twice with PBS and then resuspended in $500 \mu \mathrm{l}$ of PBS. Aliquots of the suspension (10, 20, 40, and 80 $\mu \mathrm{l})$ were added to $1 \mu \mathrm{g}$ of rHsp90 and then incubated for $1 \mathrm{~h}$ at room temperature. The resin was centrifuged at $1,000 \times g$ for 2 min and then washed three times with $0.05 \%$ Tween-20 in PBS. Bound rHsp90 was eluted with western blotting sample buffer for $5 \mathrm{~min}$ at $95^{\circ} \mathrm{C}$. The eluate was centrifuged at 
$5,000 \times g$ for $5 \mathrm{~min}$ at $4^{\circ} \mathrm{C}$, and the presence of rHsp90 in the supernatant was assessed by western blotting using an antibody to Hsp90 (Cell Signaling Technology) as described above.

\section{2-17. Inhibition of recombinant Hsp90 (rHsp90) ATPase activity}

The ATPase activity of rHsp90 was measured using an ATPase/GTPase Assay kit (BioAssay Systems, Hayward, CA). The enzyme reaction was performed in a 96-well plate by adding $50 \mathrm{ng} / \mu \mathrm{l} \mathrm{rHsp} 90$, ODN (3, 10, $30 \mu \mathrm{M}), 1 \times$ assay buffer, and $1 \mathrm{mM}$ ATP. After incubation for $30 \mathrm{~min}$ at room temperature, the absorbance at $630 \mathrm{~nm}$ was measured. One unit of ATPase activity was defined as the amount of enzyme capable of catalyzing the production of $1 \mu \mathrm{mol}$ of free phosphate per min under the assay conditions.

\section{2-18. Statistical analysis}

Data are presented as the means \pm SEM. Statistical analyses were performed using Origin Pro 8.1

(OriginLab, Northampton, MA). The statistical significance of differences was determined by one-way ANOVA (analyses other than DAI) or two-way ANOVA (analysis of DAI) followed by Bonferroni's test. In all analyses, $P<0.05$ was taken to indicate statistical significance. 


\section{Results}

\section{3-1. Screening for ODN in the genomic DNA of L. casei that decreased IL-8 secretion in Caco-2 cells}

To identify anti-inflammatory ODN, we treated Caco-2 cells with 100 plasmids containing various nucleotide fragments from the genomic DNA of L. casei and measured the secretion of IL-8 in the presence of $\mathrm{H}_{2} \mathrm{O}_{2}$. Treatment with 24 of the plasmids (No. 5, 11, 13, 36, 37, 38, 39, 41, 47, 48, 49, 50, 52, 55, 56, 57, 60, 62, 68, 73, 79, 83, 85, and 87) significantly decreased $\mathrm{H}_{2} \mathrm{O}_{2}$-induced IL-8 secretion $(P<$ 0.05 or $P<0.01$ vs. $\mathrm{H}_{2} \mathrm{O}_{2}+$ pUC19) (Supplementary Table 4). We sequenced the nucleotide fragments in each of these 24 plasmids (accession numbers AB780864 - AB780887; nucleotide sequence data are available in the DDBJ database at http://www.ddbj.nig.ac.jp/) and searched for high-frequency sequences. Among the 24 plasmids, nine sequences with eight bases were the longest sequences commonly identified in more than three plasmids (Supplementary Table 5). The sense (F) and anti-sense (R) versions of these nine sequences (18 sequences in total) were synthesized as candidate antiinflammatory ODN (Table 1). Caco-2 cells were incubated with each of the 18 ODN in the presence of $\mathrm{H}_{2} \mathrm{O}_{2}$. Treatment with 14 of the ODN (3F, 3R, 4F, 4R, 5F, 5R, 6F, 6R, 7F, 7R, 8F, 8R, 9F, and 9R) significantly decreased $\mathrm{H}_{2} \mathrm{O}_{2}$-induced IL-8 secretion $\left(P<0.05\right.$ or $P<0.01$ vs. $\left.\mathrm{H}_{2} \mathrm{O}_{2}+\mathrm{H}_{2} \mathrm{O}\right)$ (Fig. 1). 7F inhibited IL-8 secretion $(321.2 \pm 25.3 \mathrm{pg} / \mathrm{ml})$ to a greater extent than the other ODN. 


\section{3-2. Frequencies of the 14 anti-inflammatory $O D N$ in the genomic DNA of five Lactobacillus species}

To characterize the 14 anti-inflammatory ODN, we surveyed the frequency of the anti-inflammatory ODN in the genomic DNA of L. acidophilus, L. casei, L. gasseri, L. plantarum, and L. reuteri. The sequences of 3F, 3R, 5F, 5R, 8F, 8R, 9F, and 9R were seen randomly throughout the genomic DNA of the five Lactobacillus species. However, the sequences of 4F, 4R, 6F, 6R, 7F, and 7R were enriched in the genomic DNA of L. casei. The frequencies of 7F and 7R (127 - 129 per $10^{6}$ base pairs) were especially high and were similar in the seven strains of L. casei examined (Fig. 2 and Supplementary Table 1). Therefore, we selected 7F and 7R for further experiments. We used 8F, an anti-inflammatory ODN equally represented in the five Lactobacillus species, and $1 \mathrm{~F}$ as negative control.

\section{3-3. Anti-inflammatory $O D N$ decrease iNOS and COX-2 expression in macrophage-like differentiated THP-1 cells}

Caco-2 cells were used as an epithelial cell model for identification of unique anti-inflammatory ODN from the genomic DNA of $L$. casei. We subsequently confirmed the anti-inflammatory effect of the novel ODN in an immune cell model, using THP-1 that were differentiated into macrophage-like cells by treatment with PMA. The levels of iNOS and COX-2 were higher in macrophage-like differentiated THP-1 cells treated with LPS $+\mathrm{H}_{2} \mathrm{O}$ than in cells treated with $\mathrm{H}_{2} \mathrm{O}$ alone $(P<0.01)$. 7F, 7R, and 8F

significantly decreased LPS-induced iNOS expression in cells treated with LPS $+\mathrm{H}_{2} \mathrm{O}$ (relative density: $0.56 \pm 0.05,0.56 \pm 0.04$, and $0.49 \pm 0.05$, respectively, $v s .0 .86 \pm 0.09 ; P<0.05$ ). The iNOS expression 
in cells treated with 7F, 7R, or 8F did not differ significantly (Fig. 3A). However, only treatment with 7F significantly decreased LPS-induced COX-2 expression in cells treated with LPS $+\mathrm{H}_{2} \mathrm{O}(2.81 \pm 0.39$ vs. $4.78 \pm 0.49 \mu \mathrm{g} / \mathrm{g}$ protein; $P<0.05$ ) (Fig. 3B). These results indicated that only 7F inhibited LPS-induced iNOS and COX-2 expression in immune cells.

\section{3-4. Anti-inflammatory ODN ameliorate murine colitis}

The DAI, colon length, colonic MPO activity, and histopathology of the colon were used to evaluate the effects of oral administration of 7F on DSS-induced colitis. DAI in the DSS + saline group was significantly higher from days $4-7$ than in the saline group (day 4: $P<0.05$; day $5-7: P<0.01$ ). Administration of 7F significantly reduced DSS-induced colitis on days 6 and 7 (DAI: $5.50 \pm 0.56$ and 7.10 \pm 0.57, respectively, vs. $8.30 \pm 0.42$ and $9.90 \pm 0.28$ in DSS + saline; $P<0.01$ ) (Fig. 4A). A significant reduction in colon length and a significant increase in MPO activity were observed in the DSS + saline group ( $P<0.01$ vs. saline group). Administration of 7F, 7R, and 8F significantly inhibited the DSS-induced reduction in colon length $(7.07 \pm 0.27,6.17 \pm 0.18$, and $6.57 \pm 0.11 \mathrm{~cm}$, respectively, vs. $10.00 \pm 0.18 \mathrm{~cm} ; P<0.01, P<0.05$, and $P<0.05$, respectively) (Fig. 4A). Only administration of 7F significantly attenuated the DSS-induced increase in MPO activity $(0.20 \pm 0.01$ vs. $0.27 \pm 0.03 \mathrm{U} / \mathrm{mg}$ protein; $P<0.05$ ) (Fig. 4A). On histological analysis, distal colonic sections from saline group showed normal crypt morphology, whereas comparable sections from the DSS + saline group showed tissue damage, such as crypt loss and cell infiltration of the submucosal layer. In contrast, only mild tissue damage was observed in distal colonic sections from the DSS + 7F group (Fig. 4A). 
We also assessed inflammatory factors (i.e., MIP-2, iNOS, and COX-2) that exacerbate intestinal inflammation. The levels of MIP-2, iNOS, and COX-2 mRNA in the colon were significantly increased in the DSS + saline group ( $P<0.01$ vs. the saline group). Administration of 7F significantly attenuated the DSS-induced increase in MIP-2, iNOS, and COX-2 mRNA expression (0.44-fold, 0.42-fold, and 0.44-fold, respectively, vs. DSS + saline; $P<0.01, P<0.05$, and $P<0.05$, respectively) (Fig. 4B). On the other hand, administration of 1F, 7R, and 8F had no significant effect on MIP-2, iNOS, and COX-2 mRNA expression. These results showed that 7F ameliorates DSS-induced murine colitis and suggested that $7 \mathrm{~F}$ show the anti-inflammatory effects in vitro and in vivo.

\section{3-5. TLR9 and Hsp70 mediate the anti-inflammatory effect of 7F in the epithelium}

To elucidate the anti-inflammatory mechanism of 7F, we examined whether TLR9 silencing could abolish the attenuation of $\mathrm{H}_{2} \mathrm{O}_{2}$-induced IL-8 secretion by 7F. Treatment with 7F significantly attenuated $\mathrm{H}_{2} \mathrm{O}_{2}$-induced IL-8 secretion in non-transfected cells and in those transfected with scramble TLR9siRNA. Treatment with 7F also attenuated $\mathrm{H}_{2} \mathrm{O}_{2}$-induced IL-8 secretion in TLR9-siRNA-transfected cells (525.7 \pm 83.0 vs. $792.7 \pm 25.2$ pg/ml; $P<0.05)$. However, $\mathrm{H}_{2} \mathrm{O}_{2}$-induced IL-8 secretion in TLR9siRNA-transfected cells was significantly higher than that in non-transfected cells and in scramble TLR9-siRNA-transfected cells (375.7 \pm 68.0 and $315.3 \pm 44.7$ pg/ml, respectively; $P<0.05)$ (Fig. 5A). These results indicated that TLR9 silencing partially regulates the ability of 7F to attenuate $\mathrm{H}_{2} \mathrm{O}_{2}-$ induced IL-8 secretion and suggested that TLR9 is one of primary mediators of anti-inflammatory effect of $7 \mathrm{~F}$ in the epithelium. 
Next, we examined whether Hsp70 silencing abolish the attenuation of $\mathrm{H}_{2} \mathrm{O}_{2}$-induced IL-8 secretion by 7F. Treatments with 7F decreased $\mathrm{H}_{2} \mathrm{O}_{2}$-induced IL-8 secretion in non-transfected cells and scramble Hsp70-siRNA-transfected cells. However, 7F had no effect on $\mathrm{H}_{2} \mathrm{O}_{2}$-induced IL-8 secretion in Hsp70siRNA-transfected cells. The level of IL-8 secretion in Hsp70-siRNA-transfected cells (646.7 \pm 131.3 pg/ml) was significantly higher than those in non-transfected cells and scramble Hsp70-siRNAtransfected cells (366.3 \pm 61.7 and $310.3 \pm 40.7 \mathrm{pg} / \mathrm{ml}$, respectively; $P<0.05)$ (Fig. 5A). The results indicated that Hsp70 silencing abolishes the attenuation of $\mathrm{H}_{2} \mathrm{O}_{2}$-induced IL-8 secretion by 7F and suggested that Hsp70 expression mediates the anti-inflammatory effect of 7F in the epithelium.

Subsequently, we investigated whether treatment with 7F increase the expression of Hsp70 in Caco2 cells and the murine colon. Hsp70 was consistently expressed in Caco-2 cells and the murine colon. In addition, there were no significant differences in Hsp70 expression in Caco-2 cells treated with $\mathrm{H}_{2} \mathrm{O}_{2}$ or in the colons of mice administered DSS compared to Hsp70 expression in cells treated with $\mathrm{H}_{2} \mathrm{O}$ or in the colons of mice administered saline, respectively. However, Hsp70 protein expression increased significantly in 7F-treated Caco-2 cells and in the colons of 7F-administered mice (2.7-fold and 2.2-fold, respectively, vs. $\mathrm{H}_{2} \mathrm{O}_{2}+\mathrm{H}_{2} \mathrm{O}$ and DSS + saline, respectively; $P<0.05$ ) (Fig. 5B). These results showed that 7F increases the expression of Hsp70 and suggested that an increase in Hsp70 expression is necessary for the anti-inflammatory effect of 7F in the epithelium.

Finally, to investigate the mechanism underlying the effect of 7F on Hsp70 expression except for TLR9, we examined whether 7F bind to Hsp90 and inhibited its ATPase activity. rHsp90 bound to agarose resin-conjugated $1 \mathrm{~F}(80 \mu \mathrm{l})$ and $7 \mathrm{~F}(20,40$, and $80 \mu \mathrm{l})$, but did not bind to agarose resin in the absence of ODN. The addition of 1F did not inhibit the ATPase activity of rHsp90, nor did the addition of 3 or $10 \mu \mathrm{M}$ 7F. However, the addition of $30 \mu \mathrm{M}$ 7F significantly inhibited the ATPase activity of rHsp90 (12.1 \pm 0.7 vs. $21.0 \pm 2.4 \mathrm{nmol} / \mathrm{mg} / \mathrm{min} ; P<0.05)$ (Fig. 5C). These results indicated that 7F has 
a higher affinity than $1 \mathrm{~F}$ for rHsp90 and that 7F inhibits the ATPase activity of rHsp90 in a dose-

dependent manner. Therefore, 7F may increase Hsp70 expression by binding to Hsp90 and inhibiting its ATPase activity.

\section{Discussion}

In this study, we isolated 14 novel anti-inflammatory ODN from the genomic DNA of L. casei. One of these ODN (TTTTGCCG), designated as 7F, showed strong anti-inflammatory activity, as demonstrated by its ability to attenuate $\mathrm{H}_{2} \mathrm{O}_{2}$-induced IL-8 secretion in Caco-2 cells. Among five Lactobacillus species examined, 7F was uniquely enriched in the genomic DNA of L. casei. 7F also attenuated LPS-induced increases in iNOS and COX-2 expression in macrophage-like differentiated THP-1 cells and ameliorated DSS-induced murine colitis when administered orally to mice. The antiinflammatory effect of 7F in the epithelium was partially mediated by TLR9. However, an increase in Hsp70 expression was the main mediator of the anti-inflammatory effect of 7F. Inhibition of Hsp90 ATPase activity upon binding to 7F, as well as stimulation of TLR9, may regulate the expression of Hsp70.

Various anti-inflammatory ODN have been identified. The frequencies of the ODN TTAGGG and TCAAGCTTGA in the genomic DNA of Lactobacillus species were reported to be correlated with the anti-inflammatory effects of the species [17]. On the other hand, we reported previously that the antiinflammatory effect induced by L. acidophilus genomic DNA is weaker than those of other 
Lactobacillus species (L. casei, L. gasseri, L. plantarum, and L. reuteri) [4]. However, the frequencies of TTAGGG and TCAAGCTTGA in the genomic DNA of L. acidophilus and the other Lactobacillus species are similar. In the present study, 7F showed strong anti-inflammatory effects in vitro and in vivo (Figs. 1, 3, and 4). Interestingly, the frequency of 7F in L. casei was higher than those in other Lactobacillus species (L. acidophilus, L. gasseri, L. plantarum, and L. reuteri) and was similar between strains of $L$. casei (Fig. 2 and Supplementary Table 1). Therefore, the anti-inflammatory effect of $L$. casei genomic DNA may depend on the frequency of 7F in the genome. However, the frequencies of 7F in the genomic DNA of L. acidophilus and the other Lactobacillus species, with the exception of L. casei, were similar. Thus, the frequency of 7F may not determine the anti-inflammatory effect induced by the genomic DNA of each Lactobacillus species. These observations suggest the presence of speciesdependent anti-inflammatory ODN in the genomic DNA of each Lactobacillus species.

In a previous study, we showed that TLR9 primarily mediates the anti-inflammatory effect induced by the genomic DNA of Lactobacillus species [4]. Therefore, we hypothesized that 7F exerts its antiinflammatory effect through TLR9. However, TLR9 suppression only partially blocked the antiinflammatory effect of 7F in the epithelium (Fig. 5A), suggesting that TLR9 is one, but not the only, mediator of the anti-inflammatory effect of 7F. On the other hand, suppression of Hsp70 completely abolished the anti-inflammatory effect of 7F (Fig. 5A). In addition, treatment of Caco-2 cells and mice with 7F increased Hsp70 expression (Fig. 5B). These observations indicated that increased Hsp70 expression is the main signal responsible for the anti-inflammatory effect of 7F. Treatment with CpG-B ODN (TCCATGACGTTCCTGATGCT), an anti-inflammatory ODN that ameliorates the severity of inflammatory arthritis in a mouse model [27], was shown to increase the expression of Hsp70 in human embryonic kidney (HEK) 293 cells; treatment with chloroquine, a TLR9 inhibitor, abolished the CpG-B ODN-induced increase in Hsp70 expression [28]. These results, combined with those of the present study, indicate that TLR9 is a primary mediator of anti-inflammatory ODN activity. Moreover, 
stimulation of TLR9 by anti-inflammatory ODN may increase Hsp70 expression to induce the antiinflammatory effect. On the other hand, it has been reported that another anti-inflammatory ODN (ACCGATAACGTTGCCGGTGACG) binds to Hsp90 [2, 23], and the binding to Hsp90 followed by inhibition of its ATPase activity increases the expression of Hsp70 [24]. As expected, 7F bound to rHsp90 and inhibited its ATPase activity. Therefore, 7F may increase the expression of Hsp70 through the interaction with Hsp90 and thereby exert its anti-inflammatory effect. These observations suggest that Hsp90 and TLR9 are the primary mediators of anti-inflammatory ODN activity.

TLR9 acts as the primary mediator of both effects exerted by the anti-inflammatory ODN, such as 7F, and immunostimulatory ODN. Immunostimulation caused by immunostimulatory ODN is initiated by recognition of the ODN by TLR9, which is localized in the cytoplasm of mammalian cells. Thereafter, TLR9 induces the phosphorylation of myeloid differentiation factor (MyD) 88, an essential adaptor protein for intracellular signaling. It induces NF- $\square$ B translocation from the cytoplasm to the nucleus, which is followed by an increase in the production and secretion of IL-8 [29]. To assess whether 7F has the potential to exert anti-inflammatory and immunostimulatoy effects, we examined IL-8 secretion induced by 7F in macrophage-like differentiated THP-1 cells. We showed that 7F does not increase IL-8 secretion levels, while CpG-ODN 1826 (TCCATGACGTTCCTGACGTT), an immunostimulatory ODN [30], increases IL-8 secretion (Supplementary Fig. 2). These findings confirm that 7F does not exert immunostimulatory effects, and acts only as an anti-inflammatory ODN. At present, we cannot explain why the effects of ODN differ between types of ODN. Tanaka et al. reported that the difference in effects between immunostimulatory and anti-inflammatory ODN might be dependent on differences in ODN sequences [31]. They also suggested that ODN bind to different sites on TLR9 depending on their sequence, with different binding sites on TLR9 defining the effect of the ODN. We postulated that 7F might bind to different ODN-binding sites on TLR9 compared with those for immunostimlatory ODN, and might possess strong anti-inflammatory effects by not inducing inflammatory responses, such 
as IL-8 secretion.

iNOS, the inducible form of nitric oxide synthase (NOS), is induced by inflammatory stimuli such as LPS [32]. The constitutive form of NOS produces physiological levels of NO that maintain the integrity of the intestinal mucosa [33], whereas iNOS produces a large amount of NO that leads to intestinal damage [34]. Similarly, COX exists as a constitutive form, COX-1, and an inducible form, COX-2. COX-2 produces large quantities of prostaglandins and induces intestinal inflammation [35]. In several physiological and pathological conditions, iNOS and COX-2 act cooperatively and synergistically. Therefore, the levels of iNOS and COX-2 reflect the degree of inflammation. LPS regulates the expression of many genes, including iNOS and COX-2, in macrophages through the activation of mitogen-activated protein kinase (MAPK) pathways containing p38, c-Jun N-terminal kinase (JNK), and extracellular signal-regulated kinase (ERK)1/2 [36]. Lee et al. reported that a p38 inhibitor, SB203580, blocked iNOS and COX-2 expression. Interestingly, a JNK inhibitor, SP600125, blocked the LPSinduced increase in iNOS, but not COX-2, expression, while an ERK1/2 inhibitor, U0126, blocked the LPS-induced increase in COX-2, but not iNOS, expression in mouse macrophage RAW264.7 cells [37]. These results suggested that LPS increases the expression of COX-2 through phosphorylation of p38 and ERK1/2. In addition, the phosphorylation of ERK1/2 under hyperosmotic conditions was higher in embryonic fibroblasts from Hsp70-deficient mice than in those from wild-type controls; the phosphorylation of p38 and JNK did not differ between Hsp70-deficient and wild-type mice [38]. These results suggest that Hsp70 specifically inhibits ERK phosphorylation. In this study, we showed that only 7F decrease the LPS-induced increase in COX-2 expression in macrophage-like differentiated THP-1 cells (Fig. 3B). The effect of 7F on COX-2 expression was also observed in DSS-induced murine colitis (Fig. 4B). Moreover, 7F increased the expression of Hsp70 in Caco-2 cells and DSS-induced murine colitis (Fig. 5B). Therefore, 7F may inhibit ERK1/2 phosphorylation and attenuate COX-2 expression by increasing the expression of Hsp70. 
In this study, we have shown that 7F, with a phosphodiester backbone, had anti-inflammatory effects in vitro and in vivo (Figs. 2, 3, and 4). Many researchers have used ODN with a phosphorothioate backbone, in which a sulfur atom is substituted for one of the non-bridging oxygens in the ODN with a phosphodiester backbone $[2,13,14,17]$. ODN with phosphorothioate backbone have remarkable resistance to nuclease-degradation compared with those that contain a phosphodiester backbone [39]. However, some data suggests that the efficiency of intracellular translocation for ODN with a phosphorothioate backbone is lower than that for ODN with phosphodiester backbones [40]. Therefore, 7F, which is expected to have high cell permeation capacity, may exert remarkable effects in clinical applications. We believe that the use of 7F over other ODN with a phosphorothioate backbone would be advantageous.

Therapy using live Lactobacillus species has been reported to ameliorate murine colitis in various models and human IBD [1]. However, the application of this therapy with live Lactobacillus species is limited because lactic acid bacteria, including Lactobacillus species, translocate from the intestine to the blood and other internal organs in IBD patients [41, 42] and can therefore cause sepsis. In the search for ways to avoid these side effects of the therapy using live Lactobacillus species, we and other groups have shown that genomic DNA is one of the anti-inflammatory components of Lactobacillus species [2, 4]. Although genomic DNA of Lactobacillus species has potential as a therapeutic agent for IBD, the extraction and purification of high-purity genomic DNA are cumbersome, and much genomic DNA is lost. On the other hand, because large-scale synthesis of ODN is possible, ODN can be prepared more easily than genomic DNA. Given that 7F comprises eight nucleotides, it can be even more easily prepared than most other ODN, which are 20-30 nucleotides. Therefore, 7F, which has a strong antiinflammatory effect, can circumvent the problems associated with the use of genomic DNA as a therapeutic agent for IBD. Some ODN also have been evaluated in clinical trials as vaccine adjuvants for infectious diseases and as anti-allergy drugs [43], supporting our suggestion that 7F could be more easily 
used as a drug than genomic DNA.

\section{Acknowledgments}

The authors are grateful to Y. Nakashima for technical help with Lactobacillus species; and Y. Tamura and S. Egawa for construction of the DSS-induced colitis mouse model.

This work was supported by the following grants: JSPS KAKENHI (No. 24659060 and 26460181); Adaptable and Seamless Technology transfer Program through target-driven R\&D (A-STEP) of Japan Science and Technology Agency (No. AS231Z02003G); the Central Research Institute of Fukuoka University (No. 126012 and 127007).

\section{Figure legends}

Fig. 1. The effects of ODN from the genomic DNA of $L$. casei on $\mathrm{H}_{2} \mathrm{O}_{2}$-induced IL-8 secretion in Caco2 cells. Caco-2 cells were treated with $30 \mu \mathrm{M}$ ODN (1F - 9R) from the genomic DNA of L. casei for 48 $\mathrm{h}$ in the presence of $1 \mathrm{mM} \mathrm{H} \mathrm{O}_{2}$. The concentration of IL-8 in the supernatant was measured by ELISA. Data are expressed as the means \pm SEM of three separate experiments performed in triplicate. ${ }^{\# \#} P<0.01$ compared to $\mathrm{H}_{2} \mathrm{O}$; $* P<0.05$, **P $<0.01$ compared to $\mathrm{H}_{2} \mathrm{O}_{2}+\mathrm{H}_{2} \mathrm{O}$. 
Fig. 2. The frequencies of $L$. casei anti-inflammatory ODN in the genomic DNA of five Lactobacillus species. The genomic DNA sequences of $L$. acidophilus (La; three strains), $L$. casei (Lc; seven strains), $L$. gasseri (Lg; one strain), L. plantarum (Lp; six strains), and L. reuteri (Lr; five strains) were analyzed for the presence of 14 ODN (3F - 9R). Each dot represents the number of ODN per $10^{6}$ base pairs in the genomic DNA of each Lactobacillus strain.

Fig. 3. The effects of anti-inflammatory ODN from L. casei on LPS-induced iNOS and COX-2 expression in macrophage-like differentiated THP-1 cells. THP-1 cells were treated with $30 \mu \mathrm{M} 1 \mathrm{~F}, 7 \mathrm{~F}$, $7 \mathrm{R}$, or $8 \mathrm{~F}$ for $24 \mathrm{~h}$ in the presence of $3 \mu \mathrm{g} / \mathrm{ml}$ LPS after differentiation to macrophage-like cells by treatment with PMA. (A) The level of iNOS in the cellular protein extract was assessed by western blotting. $\beta$-actin was used as an internal control. A representative picture is shown in the upper panel, and the bar graph in the lower panel shows the relative density. (B) The concentration of COX-2 in the cellular protein extract was measured by ELISA. Data are expressed as the means \pm SEM of three separate experiments performed in triplicate. ${ }^{\# \#} P<0.01$ compared to $\mathrm{H}_{2} \mathrm{O}$; ${ }^{*} P<0.05$, ${ }^{* *} P<0.01$ compared to LPS $+\mathrm{H}_{2} \mathrm{O}$.

Fig. 4. The ameliorating effects of anti-inflammatory ODN from L. casei on DSS-induced murine colitis. Colitis was induced by adding 3\% DSS to the drinking water for 7 days. Saline or 1F, 7F, 7R, or 8F (2 $\mathrm{nmol} / \mathrm{g}$ mouse) was administered orally every three days from day -6 to 6. (A) Body weight, stool consistency, and stool blood were recorded daily. The DAI (score: $3-12)$ is the sum of these three 
parameters. At the end of the experiment, the length of the colon was measured, and the histopathology of the distal colon was analyzed with HE staining (original magnification $\times 16$ ). Protein and total RNA extracts were prepared from the colon. MPO activity in the protein extract was determined by a colorimetric assay. (B) MIP-2, iNOS, and COX-2 mRNA expression were measured by real-time quantitative PCR. $\beta$-actin was used as an internal control. Data are expressed as the means $\pm \mathrm{SEM}, n=$ $11-12$ mice per group. ${ }^{\#} P<0.05,{ }^{\# \#} P<0.01$ compared to saline group; ${ }^{*} P<0.05,{ }^{* *} P<0.01$ compared to DSS + saline group.

Fig. 5. Involvement of TLR9 and Hsp70 in the anti-inflammatory effect of 7F in the epithelium. (A) TLR9-siRNA-, scramble TLR9-siRNA-, Hsp70-siRNA-, or scramble Hsp70-siRNA-transfected Caco-2 cells were treated with $30 \mu \mathrm{M} 1 \mathrm{~F}$ or $7 \mathrm{~F}$ for $48 \mathrm{~h}$ in the presence of $1 \mathrm{mM} \mathrm{H}_{2} \mathrm{O}_{2}$. The concentration of IL8 in the supernatant was measured by ELISA. Data are expressed as the means \pm SEM of three separate experiments performed in triplicate $(* P<0.05)$. (B) Caco-2 cells were treated with $30 \mu \mathrm{M} 1 \mathrm{~F}$ or $7 \mathrm{~F}$ for $16 \mathrm{~h}$ in the presence of $1 \mathrm{mM} \mathrm{H}_{2} \mathrm{O}_{2}$. The cellular protein extract was then prepared. Mice were orally administered $1 \mathrm{~F}$ or $7 \mathrm{~F}$ in the presence of DSS. Protein extracts were then prepared from the murine colon. Hsp70 in the protein extracts was assessed by western blotting. $\beta$-actin was used as an internal control. A representative picture is shown in the upper panel, and the bar graph in the lower panel shows the relative density. Data are expressed as the means \pm SEM of three separate experiments performed in triplicate (Caco-2 cells) or with $n=11-12$ mice per group (murine colon). ${ }^{*} P<0.05$ compared to $\mathrm{H}_{2} \mathrm{O}_{2}$ $+\mathrm{H}_{2} \mathrm{O}$ (Caco-2 cells) or DSS + saline (murine colon). (C) rHsp90 (1 $\left.\mu \mathrm{g}\right)$ and agarose resin conjugated to 1F or $7 \mathrm{~F}(10,20,40$, and $80 \mu \mathrm{l})$ were incubated for $1 \mathrm{~h}$ at room temperature. Bound rHsp90 was eluted and assessed by western blotting. Data are representative of three separate experiments. The ATPase activity of rHsp90 was determined by a colorimetric assay in the absence or presence of $1 \mathrm{~F}$ or $7 \mathrm{~F}(3,10$, 
$30 \mu \mathrm{M})$. Data are expressed as the means \pm SEM of three separate experiments performed in triplicate. $* P<0.05$ vs. rHsp90 $+\mathrm{H}_{2} \mathrm{O}$.

\section{References}

[1] Hart AL, Stagg AJ, Kamm MA. Use of probiotics in the treatment of inflammatory bowel disease. J Clin Gastroenterol 2003;36:111-9.

[2] Rachmilewitz D, Katakura K, Karmeli F, Hayashi T, Reinus C, Rudensky B, et al. Toll-like receptor 9 signaling mediates the anti-inflammatory effects of probiotics in murine experimental colitis. Gastroenterology 2004;126:520-8.

[3] Miyauchi E, Morita H, Okuda J, Sashihara T, Shimizu M, Tanabe S. Cell wall fraction of Enterococcus hirae ameliorates TNF-alpha-induced barrier impairment in the human epithelial tight junction. Lett Appl Microbiol 2008;46:469-76.

[4] Hiramatsu Y, Satho T, Irie K, Shiimura S, Okuno T, Sharmin T, et al. Differences in TLR9dependent inhibitory effects on $\mathrm{H}_{2} \mathrm{O}_{2}$-induced IL-8 secretion and NF-kappa B/I kappa B-alpha system activation by genomic DNA from five Lactobacillus species. Microbes Infect 2013;15:96104.

[5] Grimoud J, Durand H, de Souza S, Monsan P, Ouarné F, Theodorou V, et al. In vitro screening of probiotics and synbiotics according to anti-inflammatory and anti-proliferative effects. Int J Food Microbiol 2010;144:42-50. 
[6] Malago JJ, Tooten PC, Koninkx JF. Anti-inflammatory properties of probiotic bacteria on Salmonella-induced IL-8 synthesis in enterocyte-like Caco-2 cells. Benef Microbes 2010;1:121-30.

[7] Krieg AM, Yi AK, Matson S, Waldschmidt TJ, Bishop GA, Teasdale R, et al. CpG motifs in bacterial DNA trigger direct B-cell activation. Nature 1995;374:546-9.

[8] Takeshita S, Takeshita F, Haddad DE, Isii KJ, Klinman DM. CpG oligodeoxynucleotides induce murine macrophages to up-regulate chemokine mRNA expression. Cell Immunol 2000;206:101-6.

[9] Obermeier F, Dunger N, Strauch UG, Grunwald N, Herfarth H, Schölmerich J, et al. Contrasting activity of cytosin-guanosin dinucleotide oligonucleotides in mice with experimental colitis. Clin Exp Immunol 2003;134:217-24.

[10] Zhang Z, Xiang Y, Li N, Wang B, Ai H, Wang X, et al. Protective effects of Lactobacillus rhamnosus GG against human rotavirus-induced diarrhea in a neonatal mouse model. Pathog Dis 2013;67:184-91.

[11] Majamaa H, Isolauri E, Saxelin M, Vesikari T. Lactic acid bacteria in the treatment of acute rotavirus gastroenteritis. J Pediatr Gastroenterol Nutr 1995;20:333-8.

[12] Iliev ID, Kitazawa H, Shimosato T, Katoh S, Morita H, He F, et al. Strong immunostimulation in murine immune cells by Lactobacillus rhamnosus GG DNA containing novel oligodeoxynucleotide pattern. Cell Microbiol 2005;7:403-14.

[13] Stacey KJ, Young GR, Clark F, Sester DP, Roberts TL, Naik S, et al. The molecular basis for the lack of immunostimulatory activity of vertebrate DNA. J Immunol 2003;170:3614-20.

[14] Dorn A, Ludwig RJ, Bock A, Thaci D, Hardt K, Bereiter-Hahn J, et al. Oligodeoxynucleotides suppress IL-8 in skin keratinocytes in vitro and offer anti-inflammatory properties in vivo. J Invest Dermatol 2007;127:846-54.

[15] Hemmi H, Takeuchi O, Kawai T, Kaisho T, Sato S, Sanjo H, et al. A Toll-like receptor recognizes bacterial DNA. Nature 2000;408:740-5. 
[16] Moriyama I, Ishihara S, Rumi MA, Aziz MD, Mishima Y, Oshima N, et al. Decoy oligodeoxynucleotide targeting activator protein-1 (AP-1) attenuates intestinal inflammation in murine experimental colitis. Lab Invest 2008;88:652-63.

[17] Bouladoux N, Hall JA, Grainger JR, dos Santos LM, Kann MG, Nagarajan V, et al. Regulatory role of suppressive motifs from commensal DNA. Mucosal Immunol 2012;5:623-34.

[18] Cao W, Vrees MD, Kirber MT, Fiocchi C, Pricolo VE. Hydrogen peroxide contributes to motor dysfunction in ulcerative colitis. Am J Physiol Gastrointest Liver Physiol 2004;286:G833-43.

[19] Gardiner KR, Halliday MI, Barclay GR, Milne L, Brown D, Stephens S, et al. Significance of systemic endotoxaemia in inflammatory bowel disease. Gut 1995;36:897-901.

[20] Yoshie O, Imai T, Nomiyama H. Chemokines in immunity. Adv immunol 2001;78:57-110.

[21] Kim CH, Kim HG, Kim JY, Kim NR, Jung BJ, Jeong JH, et al. Probiotic genomic DNA reduces the production of pro-inflammatory cytokine tumor necrosis factor-alpha. FEMS Microbiol Lett 2012;328:13-9.

[22] Kawashima T, Kosaka A, Yan H, Guo Z, Uchiyama R, Fukui R, et al. Double-sranded RNA of intestinal commensal but not pathogenic bacteria triggers production of protective interferon- $\beta$. Immunity 2013;38:1187-97.

[23] Bandholtz L, Guo Y, Palmberg C, Mattsson K, Ohlsson B, High A, et al. Hsp90 binds CpG oligodeoxynucleotides directly: implications for hsp90 as a missing link in CpG signaling and recognition. Cell Mol Life Sci 2003;60:422-9.

[24] Kim HR, Kang HS, Kim HD. Geldanamycin induces heat shock protein expression through activation of HSF1 in K562 erythroleukemic cells. IUBMB Life 1999;48:429-33.

[25] Tanaka K, Namba T, Arai Y, Fujimoto M, Adachi H, Sobue G, et al. Genetic evidence for a protective role of heat shock factor 1 and heat shock protein 70 against colitis. J Biol Chem 2007;282:23240-52. 
[26] Abramoff MD, Magelhaes PJ, Ram SJ. Image processing with ImageJ. Biophotonics International 2004;11:36-42.

[27] Wu HJ, Sawaya H, Binstadt B, Brickelmajer M, Blasius A, Gorelik L, et al. Inflammatory arthritis can be reined in by CpG-induced DC-NK cell cross talk. J Exp Med 2007;204:1911-22.

[28] Kuo CC, Liang SM, Liang CM. CpG-B oligodeoxynucleotide promotes cell survival via upregulation of Hsp70 to increase Bcl-xL and to decrease apoptosis-inducing factor translocation. $\mathrm{J}$ Biol Chem 2006;281:38200-7.

[29] He W, Zhang Y, Zhang J, Yu Q, Wang P, Wang Z, Smith AJ. Cytidine-phosphate-guanosine

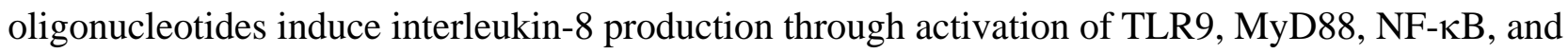
ErK pathways in odontoblast cells. J Endod 2012;38:780-5.

[30] Uehara A, Yang S, Fujimoto Y, Fukase K, Kusumoto S, Shibata K, Sugawara S, Takeda H. Muramyldipeptide and diaminopimelic acid-containing desmuramylpeptides in combination with chemically synthesized Toll-like receptor agonists synergistically induced production of interleukin-8 in a NOD2- and NOD1-dependent manner, respectively, in human monocytic cells in culture. Cell Microbiol 2005;7:53-61.

[31] Tanaka M, Ishii K, Nakamura Y, Miyazato A, Maki A, Abe Y, Miyasaka T, Yamamoto H, Akahori Y, Fue M, Takahashi Y, Kanno E, Maruyama R, Kawakami K. Toll-like receptor 9-dependent activation of bone marrow-derived dendritic cells by URAS DNA from Cryptococcus neoformana. Infect Immun 2012;80:778-86.

[32] Moncada S, Palmer RM, Higgs EA. Nitric oxide: physiology, pathophysiology, and pharmacology. Pharmacol Rev 1991;43:109-42.

[33] Whittle BJ, Lopez-Belmonte J, Moncada S. Regulation of gastric mucosal integrity by endogenus nitric oxide: interactions with prostanoids and sensory neuropeptides in the rat. Br J Pharmacol 1990;99:607-11. 
[34] Boughton-Smith NK, Evans SM, Laszlo F, Whittle BJ, Moncada S. The induction of nitric oxide synthase and intestinal vascular permeability by endotoxin in the rat. Br J Pharmacol 1993;110:1189-95.

[35] Mitchell JA, Akarasereenont P, Thiemermann C, Flower RJ, Vane JR. Selectivity of nonsteroidal anti-inflammatory drug as inhibitors of constitutive and inducible cyclooxygenase. Proc Natl Acad Sci USA 1993;90:11693-7.

[36] Guha M, Mackman N. LPS induction of gene expression in human monocytes. Cell Signal 2001;13:85-94.

[37] Lee J, Tae N, Lee JJ, Kim T, Lee JH. Eupatolide inhibits lipopolysaccharide-induced COX-2 and iNOS expression in RAW264.7 cells by inducing proteasomal degradation of TRAF6. Eur J Pharmacol 2010;636:173-80.

[38] Lee JS, Lee JJ, Seo JS. Hsp70 deficiency results in activation of c-jun N-terminal kinase, extracellular signal-regulated kinase, and caspase-3 in hyperosmolarity-induced apoptosis. J Biol Chem 2005;280:6634-41.

[39] Pisetsky DS, Reich CF 3rd. Influence of backbone chemistry on immune activation by synthetic oligonucleotides. Biochem Pharmacol 1999;58:1981-8.

[40] Zhao Q, Matson S, Herrera CJ, Fisher E, Yu H, Krieg AM. Comparison of cellular binding and uptake of antisense phosphodiester, phosphorothioate, and mixed phosphorothioate and methylphosphonate oligonucleotides. Antisense Res Dev 1993;3:53-66.

[41] Laffineur G, Lescut D, Vincent P, Quandalle P, Wurtz A, Colombel JF. Bacterial translocation in Crohn disease. Gastroenterol Clin Biol 1992;16:777-81.

[42] Porras M, Martín MT, Yang PC, Jury J, Perdue MH, Vergara P. Correlation between cyclical epithelial barrier dysfunction and bacterial translocation in the relapses of intestinal inflammation. Inflamm Bowel Dis 2006;12:843-52. 
[43] Verthelyi D, Kenney RT, Seder RA, Gam AA, Friedag B, Klinman DM. CpG oligodeoxynucleotides as vaccine adjuvants in primates. J Immunol 2002;168:1659-63. 
Table 1. Candidate anti-inflammatory ODN from the genomic DNA of L. casei

\begin{tabular}{|c|c|c|c|}
\hline \multicolumn{2}{|c|}{ Sense } & \multicolumn{2}{|c|}{ Anti-sense } \\
\hline No. & $\begin{array}{l}\text { Sequence } \\
\left(5^{\prime} \rightarrow 3^{\prime}\right)\end{array}$ & No. & $\begin{array}{l}\text { Sequence } \\
\left(5^{\prime} \rightarrow 3^{\prime}\right)\end{array}$ \\
\hline $1 \mathrm{~F}$ & САAАACTA & $1 \mathrm{R}$ & TAGTTTTG \\
\hline $2 \mathrm{~F}$ & GATGGTCA & $2 \mathrm{R}$ & TGACCATC \\
\hline $3 \mathrm{~F}$ & TGGCTGTT & $3 R$ & AACAGCCA \\
\hline $4 \mathrm{~F}$ & TTGCCGCA & $4 \mathrm{R}$ & TGCGGCAA \\
\hline $5 \mathrm{~F}$ & GATTATCG & $5 \mathrm{R}$ & CGATAATC \\
\hline $6 \mathrm{~F}$ & CGCCATTT & $6 \mathrm{R}$ & AAATGGCG \\
\hline $7 \mathrm{~F}$ & TTTTGCCG & $7 \mathrm{R}$ & CGGCAAAA \\
\hline $8 \mathrm{~F}$ & TTGTCACC & $8 \mathrm{R}$ & GGTGACAA \\
\hline $9 \mathrm{~F}$ & САTСAAAG & $9 \mathrm{R}$ & стTTGATG \\
\hline
\end{tabular}


Figure 1

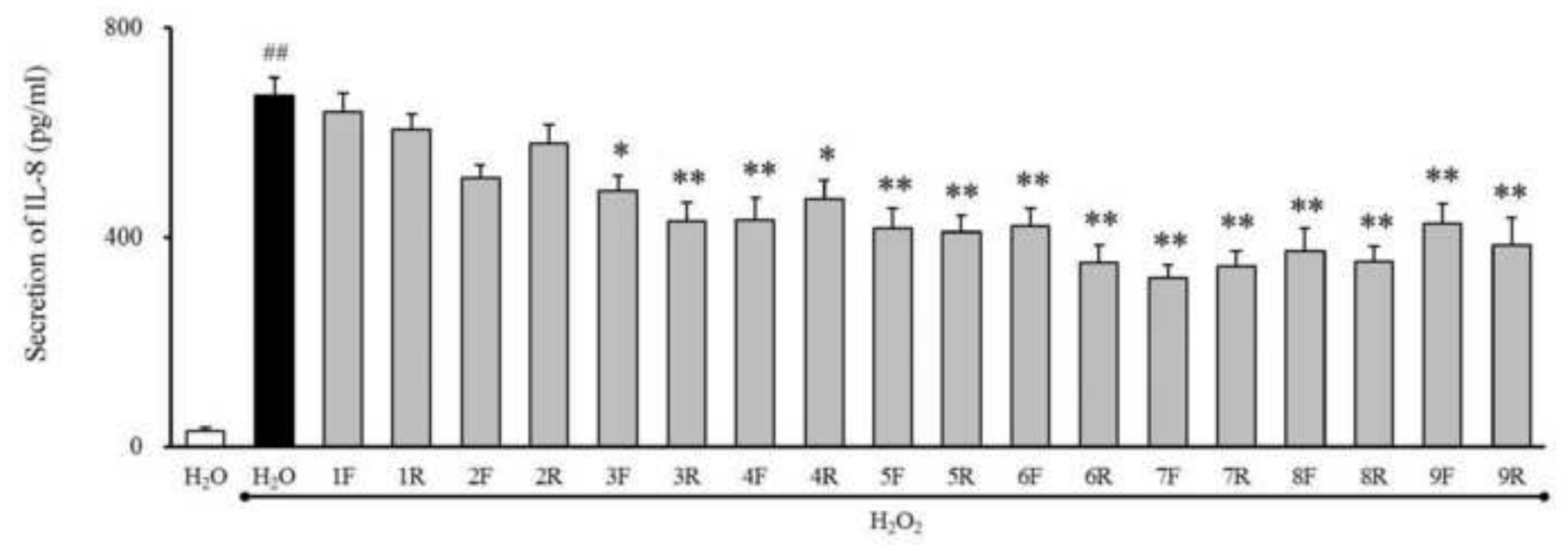


Figure 2

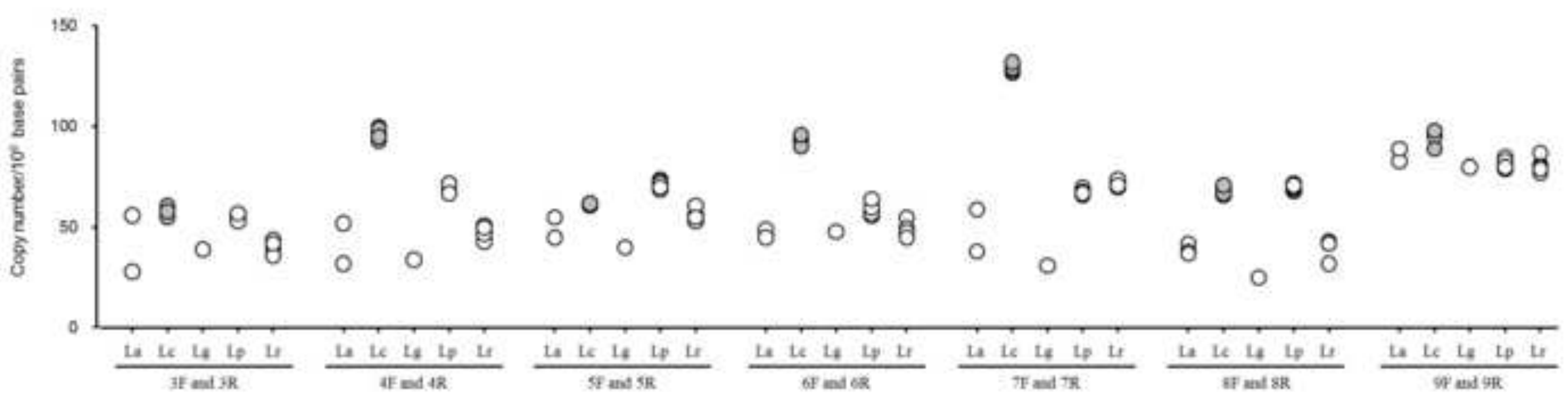


Figure 3

A
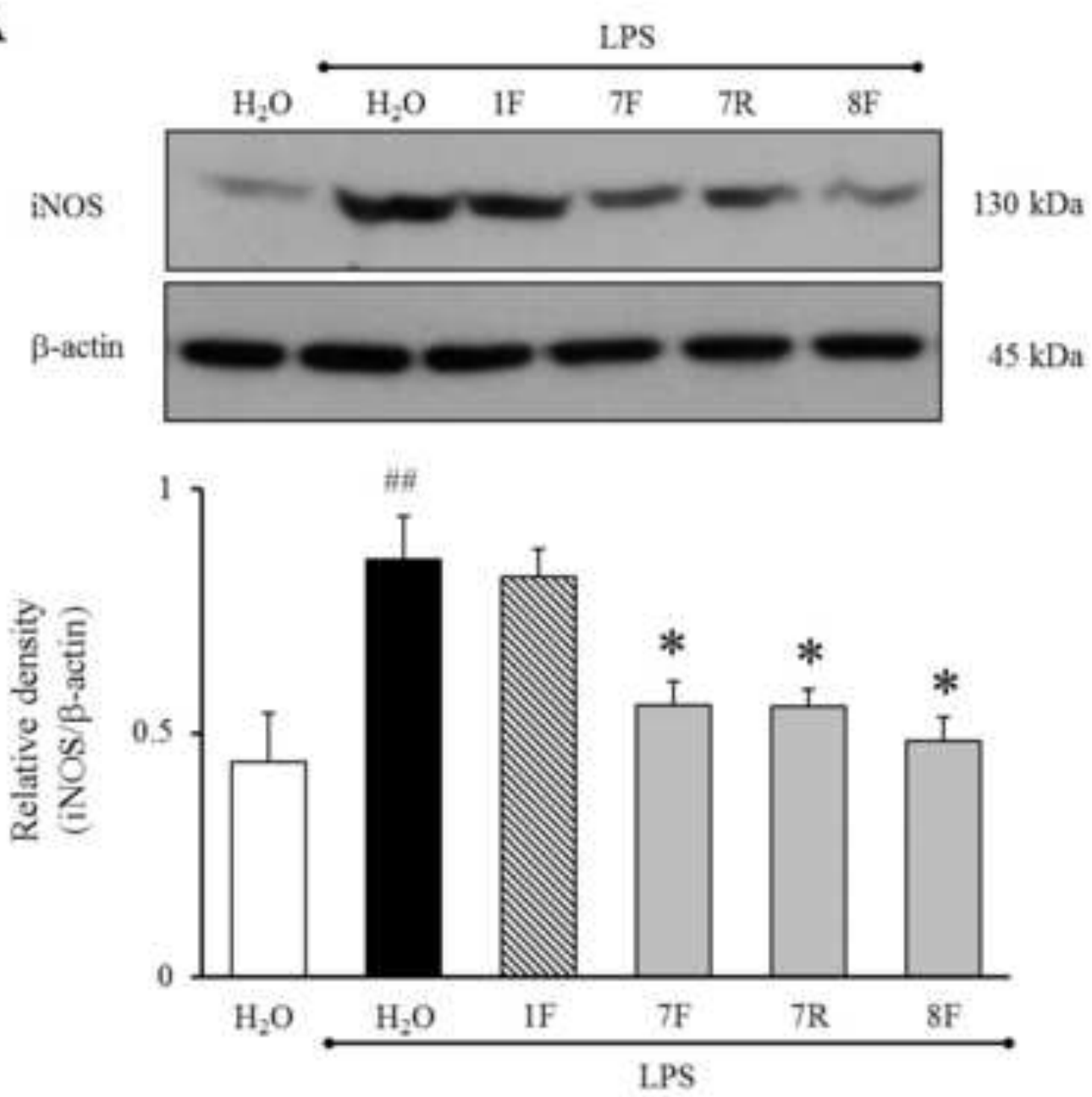

B

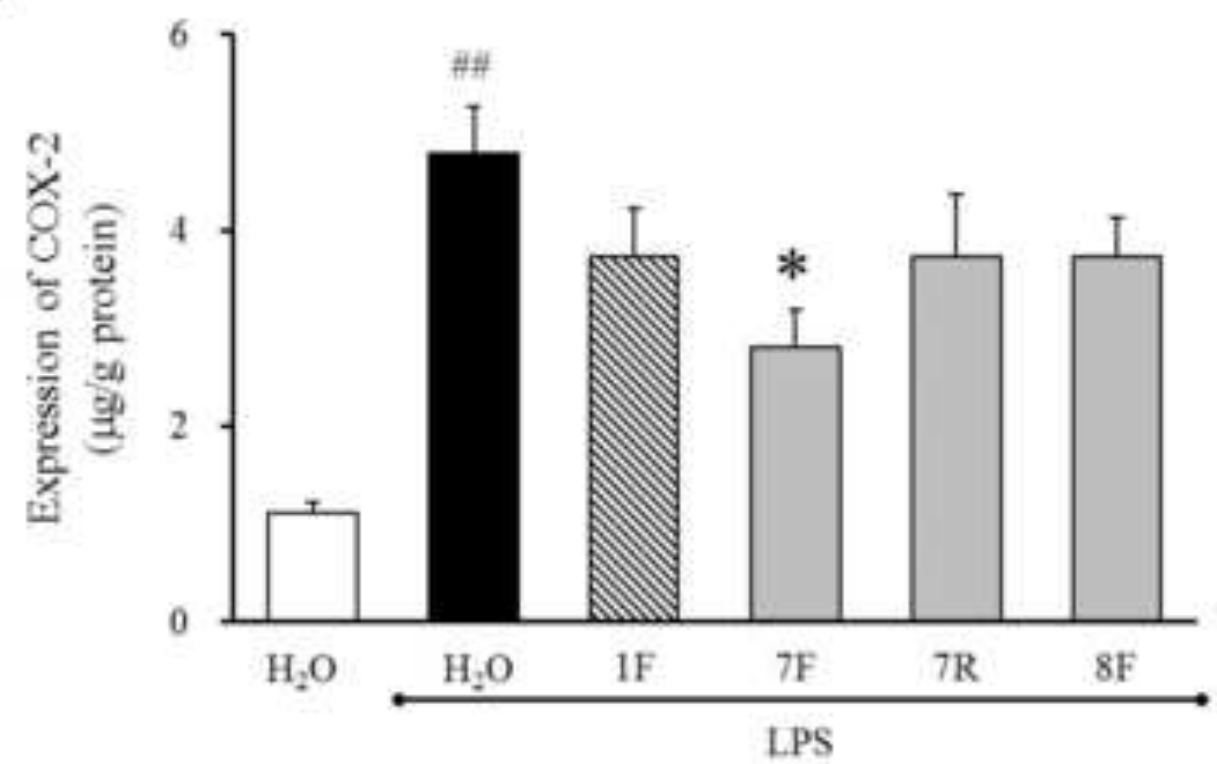


Figure 4

A
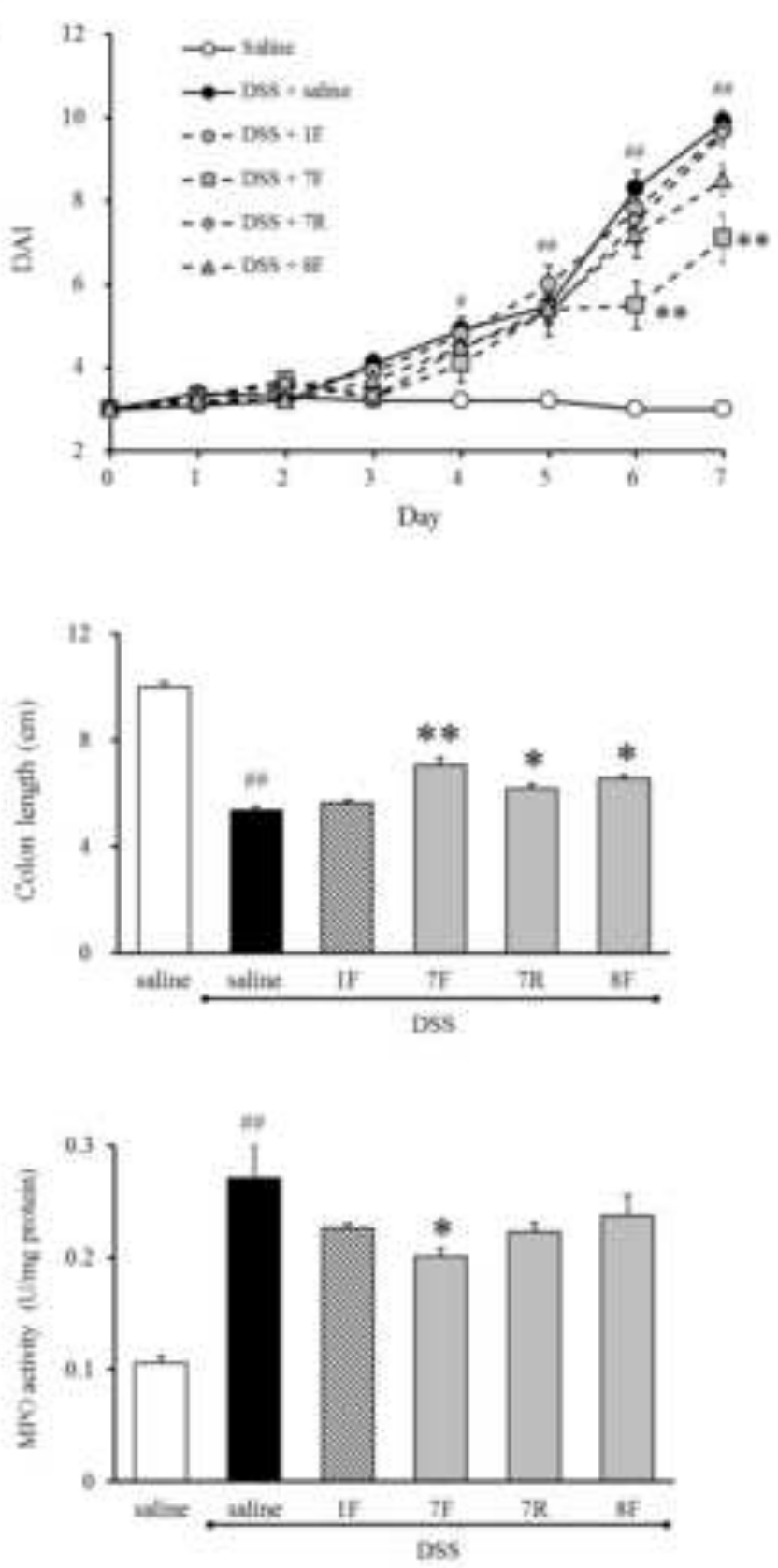

Saline

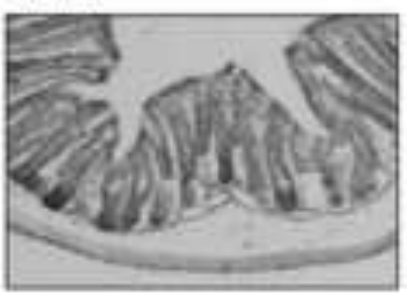

DSS + saline

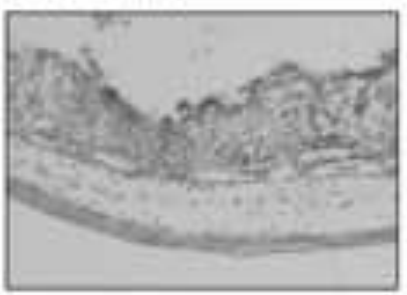

DSS $+7 \mathrm{~F}$

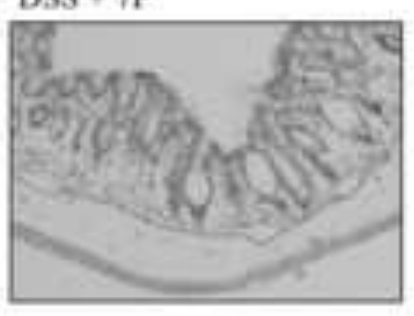

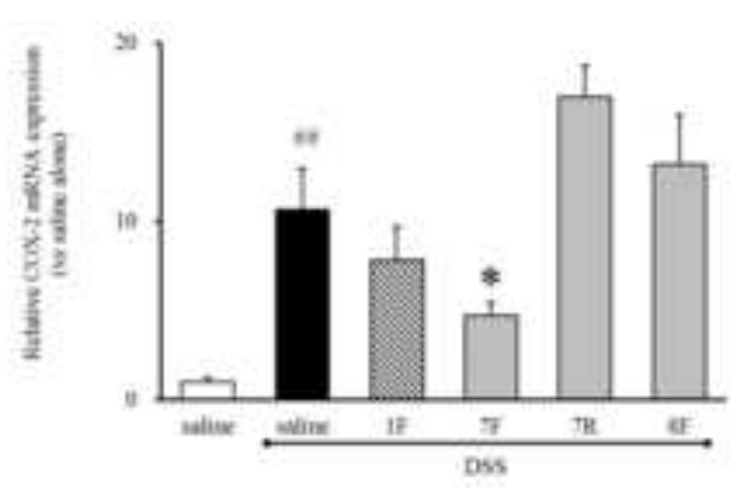

B
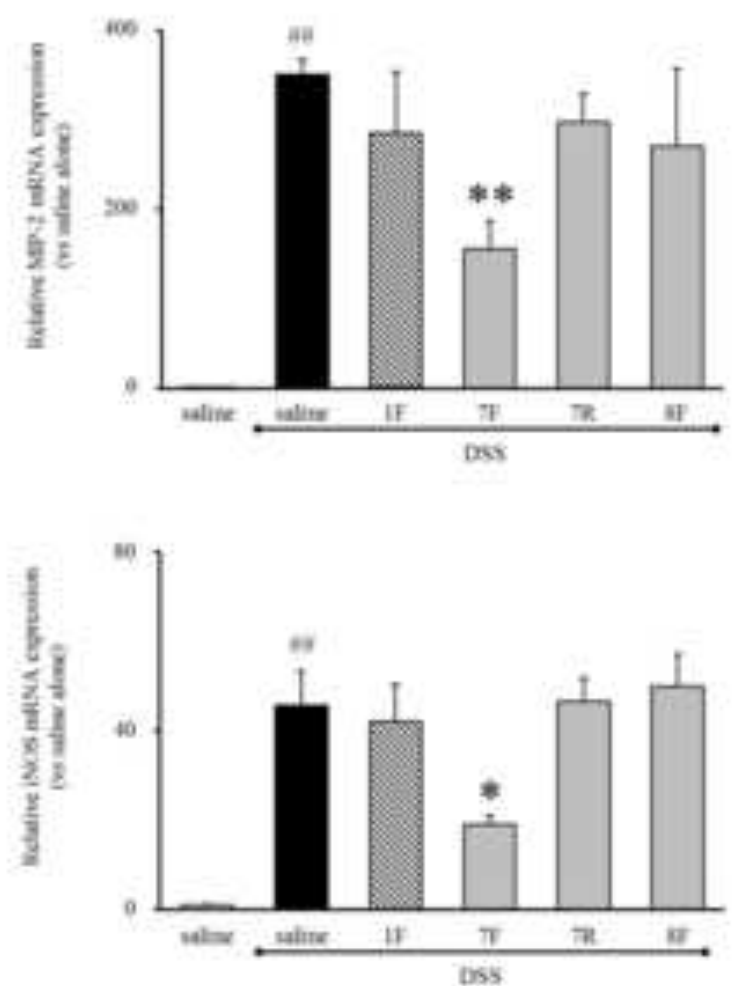
Figure 5

A

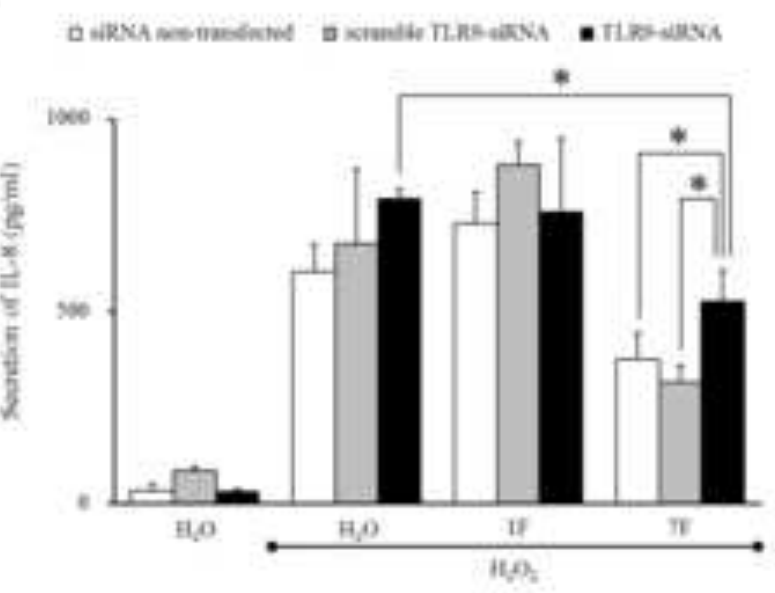

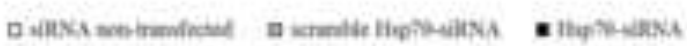

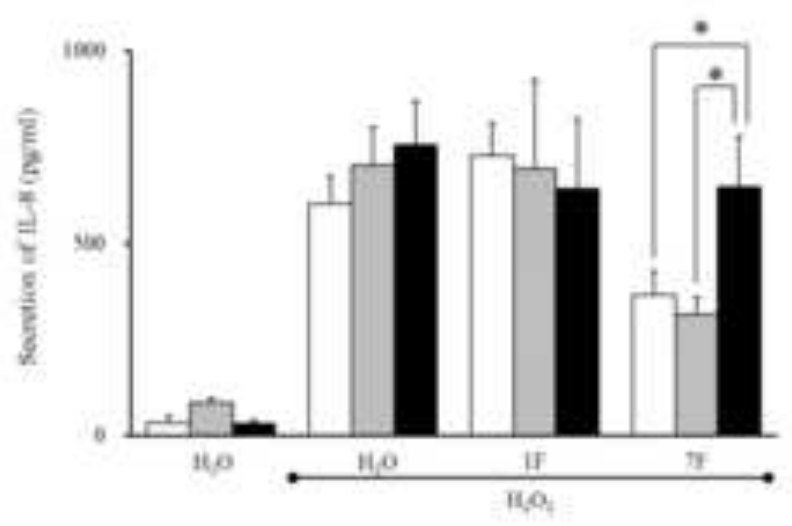

B

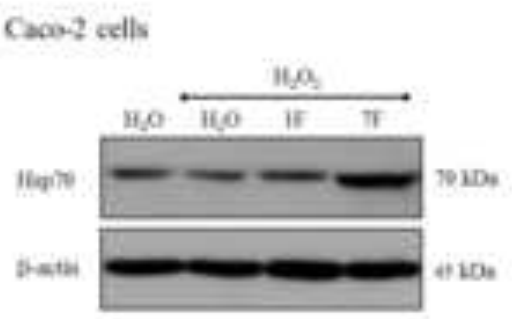

Murine colon
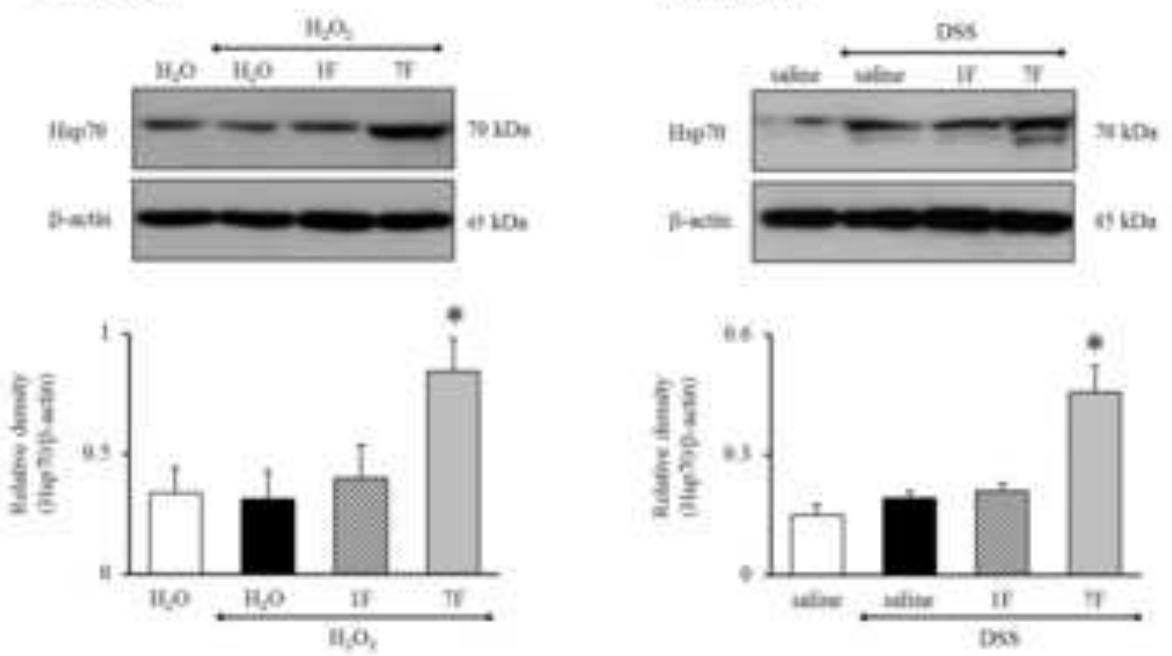

C

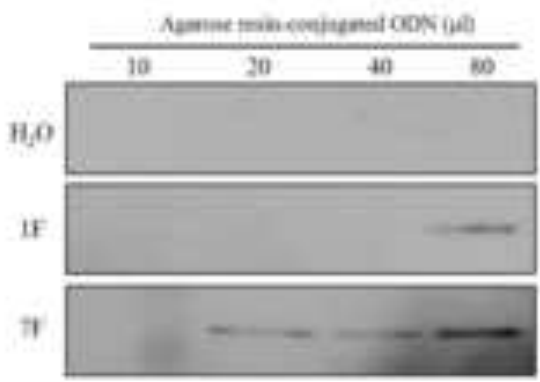

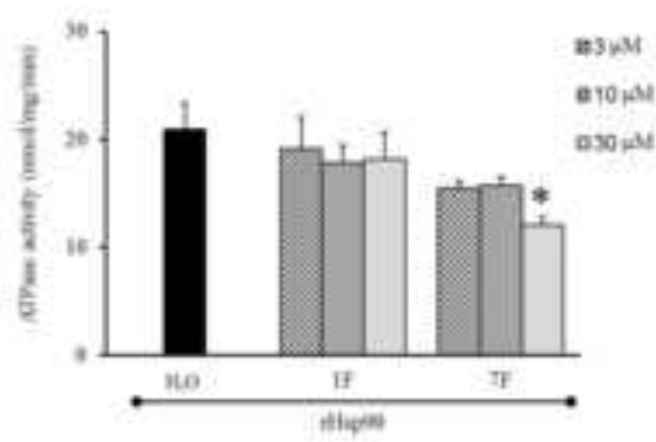

